\title{
Ethical Objections to Commercial Farming and Consumption of Genetically Modified Foods in Kenya
}

\author{
Kibaba Makokha \\ Department Of Philosophy and Religious Studies \\ Kenyatta University, Kenya \\ ktadayo@yahoo.com \\ and \\ Winfred Kyalo \\ Ministry of Agriculture, Livestock and Fisheries \\ Nairobi, Kenya \\ wmkyalo@yahoo.com
}

DOI: http://dx.doi.org/10.4314/tp.v7i1.4

Thought and Practice: A Journal of the Philosophical Association of Kenya (PAK)

New Series, Vol.7 No.1, June 2015, pp.51-76

thoughtandpractice@gmail.com

http://ajol.info/index.php/tp/index

ISSN: 2076-7714 


\begin{abstract}
Food insecurity remains one of the most pressing problems of Third World countries. The causes of this predicament are varied, ranging from drought, inadequate farming methods, poverty, among others. The responses to famine, whenever it strikes in many of these countries, have also been varied, with the most popular one being appeals for food aid from wealthy individuals, corporate bodies and the international community. However, these initiatives have not been sustainable. The need for a permanent solution has attracted varied opinions. On the one hand, some stakeholders take the view that the solution lies in genetically modified foods. On the other, some of the stakeholders are either opposed to such foods, or are cautious about them, citing potential and/or real risks associated with them. This article is premised on the view that technological innovations often raise ethical concerns and even dilemmas that ought to be surmounted in order to enhance public acceptability. In this regard, the article reflects on the ethical objections against GM technology in general, and, in particular, the process leading to the enactment of the biosafety law in Kenya.
\end{abstract}

\title{
Key words
}

Genetically modified organisms, biosafety law, UN convention on biological diversity, Cartagena protocol 


\section{Introduction}

The ugly scenes of individuals and communities ravaged by starvation are often brought into our living rooms on our television screens. The predictable response to this state of affairs is for individuals, corporate organizations and even Government appealing for food and other material donations. The most recent severe case of famine in Kenya was in 2011, when about 3 million people were faced with starvation in Northern Kenya. Predictably, there was an appeal by the Government and the local communities for assistance. In response, the Safaricom Foundation, Kenya Commercial Bank (KCB), Media Owners Association (MOA), and the Kenya Red Cross Society (KRCS) launched the Kenyans for Kenya Initiative. The main objective of the initiative was to mobilize corporate organizations and the public in general to raise 500 million shillings to alleviate the famine. This kind of response, though noble, is not sustainable, as it does not address the root cause of food insecurity.

In the light of the observations above, opinion is divided regarding the permanent solution to the problem of food insecurity. One shade of opinion routes for widespread adoption of commercial farming and consumption of genetically modified foods, which are products of genetically modified (GM) technology. To this group, GM technology is the panacea to the perennial problem of food shortage in the third world. To them, GM technology will not only assure increased food production, but also its quality. Over the years this opinion has received substantial support, and under the auspices of the UN Convention on Biological Diversity (SCBD1995), many member countries have been trying to put in place the necessary legal and regulatory framework to guide implementation. Kenya is one such country: it enacted the Biosafety Act in 2009, and has since put in place the necessary guidelines to operationalize it.

The contrary shade of opinion is either opposed to or has misgivings about the introduction, commercial farming and consumption of genetically modified foods. This group cites actual or potential uncertainties and risks that GM technology portends to human health and the natural environment. 
Both shades of opinion are supported by credible research. In Kenya, even with the necessary legal framework in place, the importation and farming of GM foods remain banned. Furthermore, as will be illustrated in this article, the Kenyan government fears public backlash if it goes ahead to implement the Biosafety Act.

It is in the light of these controversies and challenges that this article seeks to interrogate the ethical objections to the GM technology itself, the processes leading to the enactment of the Biosafety Act in Kenya and the subsequent reluctance to implement it. The article argues that GM technology raises legitimate and outstanding ethical concerns, even dilemmas, that ought to be addressed to protect consumers' individual and collective liberty of autonomy and self-determination. The article evaluates the ethical implications of the production, consumption and commercial farming of genetically modified organisms (GMOs) in Kenya. It is partly based on the findings of a research project carried out by one of the co-authors on "Stakeholders' Public Participation in Policy Formulation and their Perception towards Genetically Modified Foods in Nairobi, Kenya".

\section{The GMO Debate in Perspective}

A genetically modified organism is one into which one or more genes have been introduced into its genetic material from another organism (Barret and Flora 2000; Juma and Mugabe 1994). The resultant organism is called transgenic animal, plant or organism with genetically enhanced capacities. Genetic modification technology is a subset of biotechnology known as genetic engineering which involves the manipulation of the germ cell, that is, reproductive cell, to improve the genetic code of an organism (Kyalo 2008). The United Nations Convention on Biological Diversity defines biotechnology as the use of living systems and organisms to develop or make products, or any technological application that uses biological systems, living organism or derivatives thereof to make or modify products or processes for specific uses (SCBD 2000).

The desire to improve the quality of organisms, both human and non-human, through technology has a long and controversial history. People have sought to fulfil it through different methods including selective breeding, and the infamous eugenic 
program which involved the use of such methods as sterilization and cross breeding (Boss 1999). It was however the discovery of the molecular structure of the deoxy ribonucleic acid (DNA) by James Watson and Francis Crick in the 1950's that marked a major turning point in the field of biotechnology. This discovery ushered in the era of genetic engineering (Boss 1999, 173). With these breakthroughs, by the 1980's,scientists were already genetically modifying organisms ( food) by introducing genetic material from one organism into another, for example, taking material from fish, bacteria, viruses and insects and adding them into fruits, grains and vegetables to enhance their durability and quality (Kyalo 2008). With these developments, the era of GMO's was here with us. Through genetic engineering, scientists are able to pinpoint the individual gene which produces a desired outcome, extract it, copy it and insert it into another organism (Barrett and Flora 2000).

The revolution brought about by different forms of biotechnology has enormous potential to impact human life and the natural environment. According to Persley (2003), genetic engineering, specifically genetic enhancement, has been adopted to achieve four main objectives:

1. Change product characteristics, e.g. make products more durable.

2. Improve plant resistance to pests and pathogens.

3. Enhance productivity of organisms.

4. Increase nutritional value, e.g. Vitamin A content in foods.

In short, the revolution related to biotechnology hold enormous potential in such areas as pharmaceuticals and agriculture. Consequently, the products of genetic engineering have unprecedented impact on agriculture, human health and the environment (Kyalo 2008). It is with this in mind that advocates of genetically modified organisms view biotechnology as the panacea to the world's most pressing challenges such as food insecurity, diseases, among others. This is particularly so in the Third World, which is most afflicted by these challenges.

On the flip side, however, important concerns are raised about genetically modified foods that deserve serious interrogation. Johannes Tramper and Yang Zhu (2011) have posed the correct question: is modern biotechnology a panacea or the new Pandora's Box? In the view of this article, the enormous potential that biotechnology 
has on individuals, communities and the natural environment makes it an issue of legitimate ethical concern.

\section{The GMO Debate in the Kenyan Context}

Kenya was ready to commence commercial farming of genetically modified crops following the finalization of biosafety guidelines that paved the way to the implementation of the Biosafety Act 2009. If the Act had been implemented, Kenya would have become the fourth country in Africa to engage in commercial farming of genetically modified organisms (GMOs). There are presently only three African countries engaged in commercial GM farming, namely, South Africa, Egypt and Burkina-Faso (Adenle 2011).

However, the debate surrounding the merits, demerits and other challenges of production and consumption of genetically modified foods in Kenya appears to be far from over. In fact it is set to gain even greater prominence in Kenya in particular and in the world as a whole. In the last four years, the media in Kenya has been replete with commentaries from many interest groups, including politicians, consumers and consumer organizations, and even the scientific community voicing either their support for or opposition to the introduction or importation of genetically modified products into the country.

The members of government in Kenya expected to implement the Biosafety Law have been equally divided in their opinion. For example, on July $24^{\text {th }} 2011$, the then Minister of Public Health and Sanitation, Hon. Beth Mugo, was quoted voicing strong objections to the country's plan to import genetically modified maize to feed Kenyans who were threatened with starvation. The Minister's argument was simple and candid - the country lacked the capacity to test the suitability of genetically modified products (The Standard, 24 ${ }^{\text {th }}$ July, 2011, p.22). This, in our view, was not only a serious indictment, but at worst a negation of the whole process leading to and including the enactment of the Biosafety Act: the government was admitting incapacity to implement the Biosafety Act. 


\section{Potential Benefits of Genetically Modified Organisms}

It has already been noted in the foregoing section that the revolution related to biotechnology holds enormous potential to impact such areas as agriculture, health and environment. In the area of human health, the benefits can be both direct and indirect. In a direct way, it has been documented that transgenic animals (the products of genetic enhancement) have potential to serve as donors for organs, cells and tissues for transplants. Organ transplant is increasingly becoming an important option in health care. Indeed, it promises to solve some of the debilitating human health conditions. However, the area of transplant remains overly restrictive owing to the high cost involved world-wide (Boss 1999). Indirectly, genetic engineering can be utilized to produce crops with enhanced nutritional value. An example is the rice containing high level beta-carotene - a vitamin A precursor (Persley 2003). It is a well known fact that vitamin A deficiency is one of the leading causes of severe illnesses and child mortality (Goklany 2000). Further, due to their enhanced genetic capacity, transgenic animals can have increased performance in growth rate, carcass quality, milk production and disease resistance (Kyalo 2008). This way the products of genetically modified organisms would not only contribute to enhanced human health, but also to economic benefits. Further still, such technology can be utilized to remove or reduce allergens and toxicity from foods, or to increase antioxidant contents in food, among others (Persley 2003). In short, improved nutritional value of foods produced from GM technology will lead to improved human health and quality of life.

In addition to benefits in human health, GM technology promises potential benefits to the natural environment. One of the greatest challenges of the $21^{\text {st }}$ century is sustainable development that improves quality of both the natural environment and human life (WCED 1987). Biotechnology promises to contribute immensely to this area. For instance, through GM technology we can produce:

1) Crops that can clean up the environment by absorption of various metals and metal complexes (Persley 2003).

2) Crops that would reduce ground and surface water pollution (Goklany 2000).

3) Crops that are resistant to insect pests leading to less use of insecticides, and crops that absorb nitrogen and phosphorus at higher rates thus reducing the amounts of chemical fertilizers in use (Kyalo 2008). 
The quality of the natural environment is increasingly under threat due to factors such as high levels of emissions of greenhouse gases due to the rise in human and industrial activities. Thus the application of biotechnology in the areas mentioned above will have a net effect of improved quality of the natural environment. It is also significant that enhanced soil fertility will lower the cost of agricultural input and translate to increased food production. The problem of food insecurity in the Third World has been partly blamed on soils that have increasingly become infertile owing to excessive use of chemical fertilizers that have increased the level of alkalinity. The adoption of the GM technology would thus not only contribute to improved quality of the natural environment, but also to the efforts to mitigate the perennial problem of food shortage, particularly in the third world (Adenle 2011). Ultimately, however, the success of embracing GMOs will largely depend on the benefits obtained by the farmers in cultivating transgenic instead of conventional crops (Persely 2003).

\section{Potential Risks of Genetically Modified Organisms}

As we delve into this discussion, the question posed by Tramper and Zhu (2011) as to whether biotechnology is a panacea or the new Pandora's Box comes alive. To a very large extent, the controversy concerning whether or not to adopt GMOs revolves around the uncertainty regarding the safety of these products. The proponents of GM technology and products are strongly convinced that there are no substantial risks beyond the normal risks engendered in conventional organisms and foods. This is the most popular shade of opinion held mainly by researchers and scientists in the field of biotechnology, as well as by influential organizations involved not only in research but commercial farming and production of GMOs. The arguments on the benefits of GM technology discussed above validate this claim. For instance, The Royal Society National Academy of Science of the UK and the Commonwealth, one of the leading scientific organizations, in its endorsement of GMOs, avows that there is at present no evidence that GM foods cause allergic reactions. It goes on to assert that the risks posed by GM plants are in principle no greater than those posed by conventionally derived crops or by plants introduced from other parts of the world (cited in Newell and Glover 2003). 
The unreserved stamp of approval by such influential organizations and scientists has greatly influenced the direction the GMO debate has taken the world over. It is also commonly argued by proponents of GMOs that there is no conclusive scientific evidence that GMOs have had deleterious effects on human health. While this may be the case, prudence cautions against falling into the trap of the fallacy of argumentum ad ignorantium ("appeal to ignorance"), that is, the argument that the fact that no one has so far proved conclusively that genetically modified foods have harmed humans does not of necessity mean that the opposite is true. Logically, lack of adequate evidence cannot be sufficient reason to warrant the conclusion that they are not harmful either now or in future. In any case, as shall be shown shortly, there is considerable amount of evidence to the effect that genetically modified foods have caused harm to other animals. The irony is that it is on the very basis of experimentation done on these same animals that the acclaimed safety and efficaciousness of genetically modified foods has been predicated and popularized. This means that if there is evidence of harm to animals, the potential of harm to humans is real. We can only conclude that the widespread fear of harm, either actual or potential, from consumption of genetically modified foods makes a compelling case for ethical concern.

Uncertainty about the safety of GMOs remains of grave concern to all involved. A few examples suffice to illustrate this uncertainty. Charu Verma et. al. (2011) have argued that GMOs are inherently unsafe because GM technology presents unique dangers, namely, "the process itself creates unpredictable alterations irrespective of which gene is altered". The uncertainty is real because even if actual evidence of maleficence has not been demonstrated, both the hazards and benefits of GM foods remain difficult to predict and measure accurately, and more so particularly if we take a long term view. This is partly explainable, on the one hand, within the framework that more organisms and crops continue to be developed with novel characteristics. On the other hand we have to deal with the complexity of genetic codes and ecological and social systems in which genetically engineered crops are produced and used. This is in our considered opinion of significant ethical concern, and forms a basic premise upon which key arguments in this article are articulated in the coming sections. 
Furthermore, there are reported cases of harm arising from consumption of GM foods. One compelling case is in an elaborate report of 1989 , clearly documenting actual hazards of GM foods. In this case it was reported that more than 5000 people who had eaten high doses of L-tryptophan - a dietary supplement, presented conditions such as insomnia and depression, developed Eosinhilia Myaglia Syndrome (EMS), an illness characterized by painful and swollen muscles, rashes, gastro intestinal problems and huge numbers of white blood cells. The case was traced to L-tryptophan food supplement produced by Showa Denko KK using GM bacteria. It was noted that the new toxin had never been found in the conventional version of the product (Kilbourne, Philen, Kamb and Falk 1996).

There is also documented evidence that transgenic mice can have multiple gene insertions, higher mutation rates and greater propensity to cancer than their normally generated counterparts (Orian et. al. 1990). Additionally, the possibility of GMOs raising health concerns, for example by being responsible for the emergence of new diseases is very well envisaged. For example, Robert Anderson, a scientist in genetics, environmental issues and peace and social justice who had worked for long with Physicians and Scientists for Responsible Genetics in New Zealand, was quoted in the media unequivocally stating:

Genes, like viruses can affect the body which should warn of the potential risks of transgenic organisms as a reservoir for new diseases and as a medium for the evolution of new pathogens because of their altered physiology and biochemistry (The Sunday Standard, $14^{\text {th }}$ October, 2007).

It is quite feasible that genes transferred from foods to which people are allergic may trigger allergic reactions in consumers of these products. This is because through genetic engineering, allergens can be transferred from conventional foods into GM foods and vice versa (FAO 2001). It is also a real possibility that with a new biochemistry, genetically modified organisms may pose direct health concerns to the consumers. Indeed, "adding new genetic materials into some plants may reactivate pathways to toxicity or otherwise increase levels of toxic substances within plants" (Barret and Flora 2000). It is also envisaged that trans-genesis may alter nutritional value of foods in unpredictable ways. One possible outcome of this could be excess nutrients that may negatively affect some categories of consumers such as the elderly, 
pregnant women and infants (Lappe 1999). In addition, the possibility of accelerated problems of antibiotic resistance may result in an increase in antibiotic resistance diseases, thus posing serious challenges in the health sector (FAO 2001).

We have already argued in the section on benefits of biotechnology that apart from enriching human life in many ways, the biotechnological revolution also promises to reduce the human footprint on the natural environment. Be that as it may, however, real and/or potential risks posed by genetic modification to the natural environment are well documented. Such risks have been identified by the World Health Organization (WHO) as: risks on non target organisms, effects on biodiversity, invasiveness and development of resistance (WHO 2005).

On the hazards of GM crops on the environment and biodiversity, it is reported that in a laboratory test carried out in the US, it was demonstrated that the pollen from GM maize damaged the caterpillars of the monarch butterfly (Batalion 2000). Additionally, in commercial farming and production, there is the real possibility of cross- breeding between GM crops and the surrounding conventional vegetation. The novel characteristics of the GM crops, which may include resistance to insects and herbicide tolerance, may be passed on to these plants, with the devastating effects of creating super weeds - that will eventually require increased use of herbicides (Barret and Flora 2000). This would then be counterproductive, as it would effectively nullify any gains envisaged in reduced use of herbicides as an environmental benefit of GMOs. It is with the foregoing in mind that we evaluate the ethical objections to GMOs in Kenya.

\section{Ethical Concerns about GMOs in Kenya}

The foregoing discussion reveals that in GMOs we see a convergence of anthropocentric, biocentric and ecocentric concerns, as any changes brought about by these organisms will affect humans, other living organisms and the ecosystem as a whole. Ethics as a normative philosophical inquiry is relevant in this context to help us articulate the value dimension of the issues related to the effects of GM technology and products. One of the central questions of normative ethics is "What makes actions 
right or wrong?" Put differently, ethics asks: "Why ought moral agents to do certain things and not others?"

In this section we discuss some of the ethical objections raised against the process that led to legislation about the production and consumption of GMOs in Kenya. We proceed from the premise that all technological innovations raise a plethora of ethical concerns, challenges and even dilemmas. Presently there is a palpable resistance to production and consumption of GM foods around the world. However, it is not the purpose of this article to put forward moral arguments for the outright rejection of biotechnology per se. This is essentially because any technological innovation, biotechnology included, is part of human striving, and we cannot stop humans from venturing into new areas of knowledge. Thus the old argument by a few conservative opponents that genetic engineering is unnatural commits the naturalistic fallacy. The very obligation to satisfy the human right to knowledge is itself adequate justification for research in biotechnology. Technology as a dynamic human striving is, in the words of Hilhorst (1994), "not neutral but purposeful". This makes the embracing of any technology a legitimate subject of normative assessment.

In normative ethical theory, the easiest way to justify GMOs is from a consequentialist perspective. The utilitarian theory, for instance, focuses on the end result of actions or processes to determine their rightness or wrongness. Thus it is very close to common sense reasoning. Consequently, utilitarianism is a potent tool for assessing the actual impact of the GM technology. From the reflections in the preceding sections, it is clear that sufficient considerations exist to justify adoption of GMOs on consequentialist grounds. In an earlier section the actual and potential benefits of GMOs were enunciated, and they provide consequentialist justification for GMOs.

The principle of beneficence could also easily be invoked to justify GMOs. This principle requires that we act so as to promote the welfare of others (Shannon 1993). If one of the main arguments for GMOs, particularly in the Third World, is to alleviate food insecurity and therefore promote overall human well-being, GMOs would find sufficient justification within the duty of beneficence. Indeed, GMOs would afford those who suffer the debilitating effects of perennial food shortages a 
fair opportunity to realize their well-being. Making a case for adoption of biotechnology in Africa, Adenle (2011) has enunciated the economic and other benefits gained from biotechnology by the four African countries that have embraced it.

However, considering that research and technological advancement ought to be channeled towards promoting the greater good of humanity and that of the natural environment, an interrogation of the ethical response to the challenges posed by widespread use of GM foods is in order. In so far as ethics in relation to GMOs is concerned, we pose with Hilhorst (1994) four pertinent questions:

1) When do people cause harm to themselves, and are they justified to do so?

2) When do people act at the expense of other people, present, past and future generations and the natural environment?

3) When are people justified to make fundamental decisions on behalf of others?

4) At the cost of whom and what has technology been pursued?

This article does not pretend to answer these questions definitively, but attempts to shed some light on some key ethical concerns in the GMO debate. To do this we shall restrict ourselves to some fundamental ethical principles that provide useful guidelines in debating normative issues.

\section{The Principle of Informed Consent}

The principle of informed consent is important in decision making, and therefore serves a critical role in ethics. Generally, when one consents to something, he/she assumes not only control but also responsibility for his or her actions. Thus consent protects autonomy and self- determination, and ensures that people are not easily manipulated, deceived and exploited. In the context of the debate as to whether or not to adopt the use of genetically modified crops, it provides a platform to discuss the value implications of the technology and the process leading to its adoption.

Shannon (1993) identifies four main criteria by which to determine whether or not consent is genuine, namely, competence, disclosure, comprehension and voluntariness. Competence refers to the mental capability of a person to make a 
reasonable decision. This is the prerequisite for consent. It emphasizes the inextricable link between being rational and moral in decision making.

Disclosure refers to the actual information that is provided to the person(s) whose consent is being sought. It is critical to the facilitation of consent, as it delves into the substance or content which is the subject of the consent negotiation. It affirms the adage that "information is power". Information thus empowers a person to decide whether or not to consent.

Comprehension is the ability to make sense of the information. It is one thing to have information, but quite another to make sense of it and to benefit from it. Thus comprehension ensures that the recipient of the information is able to utilize it to make a reasonable choice.

Finally, voluntariness refers to being in a position to make a choice that is not predetermined by the party seeking the consent. It means being in a position to make a free choice. Voluntariness therefore not only assures an individual the freedom of choice, but also enhances ownership of the said choices. Voluntariness helps to eliminate two major impediments to free choice, namely, undue influence and coercion (Shannon 1993).

Thus the pertinent question pursued in this article is: can the widespread adoption of GMOs, as envisaged in Kenya, satisfy the stringent criteria of informed consent to the would be consumers as outlined above?

In Kenya, we see one major objection to the adoption of GMOs arising from challenges of informed consent. To satisfy the requirement of informed consent on the standard of disclosure, the information disclosed must be relevant, accurate and sufficient. In the case of genetically modified crops and foods, the criterion of disclosure would be satisfied if and only if the actual or potential benefits and hazards are clearly disclosed to the prospective consumers. Furthermore, because of the likely widespread impact of GMOs, consent would be genuine only if communities are sufficiently consulted to create public awareness and acceptance. 
Moreover, in Kenya as in many other Third World countries, studies have regrettably shown that public participation in debate on GMOs has not been adequately done. For example a study on stakeholders' participation in biotechnology policy formulation in Kenya by Kyalo (2008) showed that only $20 \%$ of the identified stakeholders participated. These findings are corroborated by studies in other countries. Thus the main predicament is that public participation is very low, and yet there exist many complexities and dynamics regarding GM foods that may come into conflict with the values of the potential consumers (Kyalo 2008).

The uncertainties surrounding GM crops and foods, some of which have been discussed in an earlier section of this article, provide a compelling argument for the need to attain the highest threshold of disclosure. Yet this threshold has not been met in Kenya. Consequently, any purported consent that was sought from Kenyan consumers before the enactment of the relevant law was not genuine. This failure to adequately involve critical stakeholders and the general public may undermine the Cartagena Protocol on biosafety. The Cartagena Protocol provides in Article 23 (SCBD 200) that parties shall:

a) Promote and facilitate public awareness, education and participation concerning safety, transfer, handling and use of living modified organisms in relation to the conservation and sustainable use of biological diversity taking into account risks to human health;

b) Endeavour to ensure that public awareness and education encompasses access to information on living modified organisms.

Without accurate, relevant and sufficient information, the adoption of GMOs may expose the consumers to serious risks that they would have avoided had they stuck to the conventionally bred crops. Failure to fulfill the outlined criteria of informed consent greatly compromises the genuineness of consent. We share the commonly held wisdom that cautions responsible restraint and suspended action in a situation of ignorance about indirect or delayed consequences of any technology, particularly when the envisaged effects or consequences may be harmful and/or irreversible. This is particularly crucial to the Third World countries whose "limited capacity to cope with the manner and scale of known and potential risks associated with living modified organisms" is well acknowledged (SCBD 2000). 
In the case of GMOs, the Cartagena Protocol on Biosafety (SCBD 2000) had already acknowledged the potential safety risks involved and recommended the precautionary principle as had been proposed by the Conference of the State Parties to the Convention on Biological Diversity. The precautionary principle essentially requires delayed decision making, in order to take due care in anticipating unforeseen negative implications of a withheld decision. The scientific uncertainty of GMOs as demonstrated in earlier pages of this article is sufficient reason to warrant the application of the precautionary principle.

In Kenya, the inadequate scientific capacity to evaluate GM products was acknowledged by the then Ministry of Public Health and Sanitation, and also by the Kenya Plant Health and Inspectorate Services (KEPHIS) (Sunday Standard $4^{\text {th }}$ July, 2011). This acknowledgement makes the case for the application of the precautionary principle even more ethically compelling. In addition, Kenya, being a signatory to the Cartagena Protocol, is legally obligated to uphold this principle. Thus while GM crops and foods promise greater relief in mitigating the problem of food insecurity, in the light of uncertainties related to the GM technology, the precautionary principle remains a reasonable ethical guide in decision making.

Kenya may still fall short of satisfying other criteria of informed consent, particularly voluntariness, which, as noted above, is satisfied only when a choice made is free from any form of manipulation, coercion or undue influence. As argued in the preceding pages, both inadequate standards of disclosure and comprehension severely restrict the voluntariness of the action, and thus render any consent a nullity. However, the more pertinent question is: are Third World countries in a position to consent genuinely in the case of GMOs? The asymmetrical structural relations that exist between the materially wealthy countries of the north and the Third World countries render the latter countries politically, economically and scientifically too weak to resist exploitation and manipulation by the multinationals that control the GMO research and industry.

The foregoing argument is succinctly articulated by Nvindi - a member of the Kenya Biodiversity Coalition (KBioC) - who was quoted in the media as stating that "for the 
poor nations, whether or not to adopt genetically modified products is hardly an objective decision for governments and farmers. Rather, it is presented as take-it-orperish prescription. The argument goes that, by planting high-yielding GMOs contrasted to the traditional variety, food sufficiency would be guaranteed" (The Standard, $5^{\text {th }}$ May, 2011). Commenting specifically on the debate between the proGMO group (spearheaded mainly by the multinational companies) and the advocates of conventional agriculture, preceding the passing of the Biosafety Law in Kenya, Nvindi observed that "it was apparent genuine debate on the merits and demerits of the GMOs had been subverted by powerful, vested interests".

It is apparent that poor countries and farmers often find themselves in vulnerable situations that severely restrict their genuine freedom to make informed and voluntary decisions, thereby rendering them incapable of genuine informed consent. Yet exploiting and manipulating the uniquely weak situations of Third World countries to make them embrace GMOs simply amounts to a violation of the moral duty to refrain from exploiting the vulnerable.

\section{The Principle of Respect of Persons}

The principle of respect of persons is predicated on the intrinsic value of persons which is rooted in their humanity. Emmanuel Kant captures the essence of this aptly when he argues that moral imperatives require of moral agents to respect the dignity, integrity and value of persons as ends and not as mere means (Kant 1952). According to Shannon (1993), the principle of respect of persons requires of moral agents two important ethical duties.

First, there is the duty to treat persons as autonomous agents. This essentially means recognizing individuals' right to self -determination. In other words, the principle lays an obligation on moral agents to respect a person's freedom to choose what should happen to him/her and what should not happen to him/her. It further requires that we respect the individual's decisions to the extent that they are competent. This opportunity is afforded only when adequate standards of informed consent as discussed in the preceding section are satisfied. 
The second requirement of the principle of respect of persons is the duty to protect persons with diminished autonomy. This is premised on the recognition that not all persons and communities can be autonomous: some intervening factors may compromise their capacity for autonomy. To the extent that capacity for acting autonomously is impeded, the principle of respect of persons requires that such persons and communities be protected from possible harm, fraud, deception, exploitation and manipulation. It is a standard ethical requirement that such persons and communities be guided about the likely consequences of their actions.

In Kenya, because of the inability to sufficiently meet the requirements of informed consent, the process leading to legal adoption of GMOs may also fall short of the ethical requirements of the principle of respect of persons on both standards outlined above. The principle of respect of persons would require that even if we are motivated by a noble desire to alleviate the suffering caused by hunger, if harm may be occasioned by the means used to achieve that end, we must re-evaluate the options. This principle, in our view, remains a reasonable guide in the case of the decision to adopt or not adopt GMOs, particularly in Third World countries. As shown earlier on in this article, there are real and potential harms of GMOs. This means that the GM technology ought to be subjected to the highest standards of the requirements of the principle of respect of persons. In the same breath, the principle of respect of persons may also require sensitivity to the socio-cultural, ethical, and religious values and sensibilities of the consumer communities. It is well noted with concern that the adoption of GM crops and foods may offend certain ethical, socio- cultural and religious values and sensitivities of some communities. A case in point is the use of transgenic organisms (the mixing of genes in organisms across species) for food and as organs for transplant. Such measures may seriously upset cultural and religious values on dietary requirements by some communities. For instance, organisms that may contain the genetic material of pigs would be highly offensive to Muslim and Jewish communities who regard pigs as unclean. One may counter this view by arguing that sufficient labeling of GM crops and foods will adequately protect consumer choice and autonomy. This argument, though valid, is operationally not feasible if contextualized, particularly within Third World countries with feeble capacities to monitor compliance. Indeed, it is genuinely feared that a lot of unlabeled 
or mislabeled GM products will or have already found their way into the Kenyan market unnoticed in spite of the ban imposed by government.

Furthermore, it is still plausible to argue that even if proper labeling is done, the question of whether the vulnerable populations have genuine choice remains real and of legitimate ethical concern. Two arguments suffice to support this view. First, as earlier observed, no adequate education and participation has been facilitated to raise the requisite awareness for informed choice. The majority of the consumers therefore remain largely unaware of the risks of GMOs. Second, with the widespread adoption of GM technology, the conventionally produced foods are likely to be more expensive than the GM foods. The cost per se would therefore deny the poor members of the population genuine choice.

\section{Inter-generational and Inter-species Justice}

The principle of inter-generational justice is predicated on the assumption that future generations have rights which may be jeopardized by the choices and actions of the present generation. As already pointed out, real concerns exist about the potential hazards of GMOs, many of which may have long term consequences that remain largely unknown. In the light of this, a pertinent ethical question is: to what extent can the present generation justifiably assume risks on behalf of future generations? (Smith 1997).

Furthermore, GM technology is evolving, so that its real impact may not be felt in the present. As such, the unknown and unforeseen consequences of GMOs may affect future generations on a larger scale than they may the present generation. In addition, due to the uncertainties that surround GMOs, it may warrant experimentation on humans for humanity to get to know their real impact. In fact, it may well be the case that those already consuming GM products are unknowingly playing guinea pigs in the experimentation without their informed consent. Most importantly, the effects may take a long time to be felt by future generations. This would be an indictment on the present generation for the serious violation of the fundamental rights of the affected members of future generations. 
In response to the foregoing concern, proponents of GM technology may invoke the principles of proxy consent and double effect.

While proxy consent may be relied upon to make critical decisions on behalf of others who for some reason may not be able to make decisions on their own, the uncertainties surrounding the GMOs raise concerns about the applicability of this principle in this context (Wrigley 2007). In ethical theory, proxy consent traditionally offers little guidance on assuming responsibility on behalf of future persons. In the case of GMOs, given that their real impact may be on future generations rather than on the present one, the threshold of assuming risks on their behalf must be high.

The principle of double-effect may also be invoked to justify some actions that may have deleterious consequences on others. It is helpful in evaluating the moral justifiability of certain harms and risks in some situations. The principle, sometimes known as situation ethics, provides that "an act which is otherwise ethically objectionable may be morally acceptable if it is the inevitable and unavoidable consequence of carrying out a primarily morally desirable intervention" (Shannon 1993, 130). According to Shannon (1993, 6), the principle of double effect must satisfy the following four conditions:

1) What we are going to do must not be evil or wrong.

2) The harm we are considering must not be the means of producing the good effect.

3) The evil or harmful effect may not be intended, but merely permitted and tolerated.

4) There must be proportionate reason for performing the action in spite of the consequences the act has.

The principle of double effect is a valid ethical guide to calculating the risks and harms related to the adoption of some GM foods. However, if the GM technology causes changes that are irreversible, then on the basis of the criteria outlined above, we cannot rely on this principle to justify such intervention.

Further, Barrett and Flora (2000) noted that widespread genetic modification may have a negative impact on the natural environment in such ways as environmental degradation, irreversible damage to the environment, modification of species, the undermining of biodiversity, among others. These possibilities further raise fundamental concerns that may render the adoption of GMOs ethically objectionable. In the light of emerging biocentric and ecocentric ethical sensitivities regarding the 
natural environment, Hilhorst (1994) raises four questions that are pertinent to this debate:

1. What are the limits of human control of genetic destiny?

2. To what extent are humans justified to live at the expense of the natural environment?

3. To what extent can we justify the exercise of the human ability to create new forms of life, e.g. animals?

4. If animals have rights, can we justify cloning and engineering them purely as means to human ends?

These and other questions raise legitimate concerns about the integrity of species and the value of other beings such as wild animals. For example, animal rights ethicists strongly believe that animals have intrinsic value that ought to be recognized and respected by human moral agents. Thus any technology that treats animals as mere means for human purposes severely violates the morality predicated on biocentric and ecocentric arguments. It is not within the scope of this article to venture into the controversies of animal rights ethics, but the welfare of animals and that of the natural environment is of legitimate ethical concern. The net effect of widespread adoption of genetic engineering and transgenesis is the inevitable and widespread comodification of animals. This comodification may undermine the integrity and sustainability of the biotic community.

A more pertinent concern in the GMO debate is the possible inclusion of human genetic material into other animal species and vice versa. This, as alluded to in the preceding pages, not only raises the question of the integrity of species, but obviously upsets dietary sensibilities and concerns among many communities. Most importantly, it raises fundamental concerns about the question of keeping genetic boundaries among species. These are pertinent ethical concerns, but they cannot be sufficiently dealt with in this article .

\section{The Principle of Non-maleficence}

The principle of non-maleficence stipulates that moral agents have a duty not to cause harm to people (Shannon 1993, 7-8). Thus it presupposes the principle of beneficence, which is a positive duty requiring moral agents to contribute to the well-being of 
others. Non-maleficence is a negative moral duty which obligates persons to refrain from causing harm. The principle is based on the simple reasoning that if we can not benefit others, probably because we do not have the capacity to do so, at least we ought not to cause them harm. The principle also incorporates the duty not to expose people to the risk of harm.

In the context of the GMO debate, the principle of non-maleficence would require that if we cannot help to solve the problem of food insecurity for the poor, at least we have a duty to refrain from causing them further harm. To the extent that GMOs may expose consumers to the risk of harm that is beyond the risk to which they are exposed through consumption of foods from conventional crops, unless the harm is unavoidable, those who put in place policies that allow and encourage the use of GMOs violate the principle of non-maleficence. The same obligation that we owe fellow human beings not to cause them harm when we can avoid doing so can extend to the natural environment. McFague (1993) has advanced a similar line of thought by asserting that nature is the "new poor", and hence deserves the special obligation that human beings owe to poor and oppressed fellow humans.

\section{The Legal Framework for GMOs in Kenya: An Evaluation}

The Conference of the State Parties to the Convention on Biological Diversity, at its second meeting held in November 1995, established an Ad Hoc working group to develop a draft protocol, known as the Cartagena Protocol on Biosafety to the convention on biological Diversity (SCBD1995). It was adopted by the conference of state parties on $29^{\text {th }}$ January, 2000, and came into force in 2003. It provides an international regulatory framework to ensure biosafety among the state parties. Kenya signed the Cartagena Protocol in 2000, and subsequently ratified it in 2003, way before the enactment of its own laws on Biosafety.

The journey to the creation of a legal framework to regulate biotechnology in Kenya was long and controversial. The search culminated in the signing of the Biosafety Act in 2009. The Act created the National Bio-safety Authority to operationalize it. It is commendable that the membership to this Authority is broad based, including significant stakeholders such as farmers, consumers, experts in biotechnology, law, 
among others. The Authority commits itself in its objectives, inter alia, to ensure the safety of human and animal health, and to promote the protection of the natural environment. To achieve these goals, the Authority has, among others, the following two key objectives:

1) To promote awareness and education among the general public in matters relating to biosafety.

2) To provide the legal framework to mitigate the potential risks arising from biotechnology and protect the consumers, environment etc.

These objectives are in tandem with the Cartagena Protocol on Biosafety. They are crucial because they reflect the reality that biotechnology affects people, both positively and negatively, so that the law is a major instrument to mitigate any challenges that may arise.

It is not within the scope of this article to interrogate the Biosafety Act and the National Biosafety Authority. However, of great interest to this article are the questions: is the enactment of the law a panacea to the challenges arising from biotechnology? Does it effectively mitigate the concerns about inadequate public awareness, participation and education in biotechnology, and specifically public concerns about GMOs? In response to these concerns, two issues merit a brief discussion.

The first issue concerns the process leading to the enactment of the Biosafety Act. Studies show that public participation by various stakeholders was not adequate in the run-up to the writing of the act. For instance, a study by Kyalo (2008) showed that significant segments of society, including University lecturers, Scientists, Industry players, NGOs and other stakeholders reported low levels of participation in the drafting of the Biosafety Bill. This was a violation of Article 23 of the Cartagena Protocol on public participation as cited in an earlier section of this article. The net effect of this is that the majority of Kenyans, including the elites in Academia and industry, as well as the general public, remain largely unaware of the potential benefits and risks of biotechnology. The attitude and actions of the Kenyan government after the enactment of the law lends credence to this view. The government has been reluctant to allow the importation and commercial farming of GM crops, even after putting in place the requisite legal framework and guidelines. 
This reluctance, in our view, not only betrays the government's lack of confidence in the legal instruments and its other capacities to guide biotechnology, but also its fear of a backlash owing to the low levels of public awareness about genetically modified crops and biotechnology in general.

Secondly, the enactment of the Biosafety Act, the creation of the National Biosafety Authority, and the finalization of the biosafety guidelines have not helped matters. The Authority, whose foremost objective, as noted a little earlier, is to promote public awareness and education on matters relating to biosafety, has not done much in this regard. This failure has denied the country the opportunity to build public confidence in biotechnology in general, and in GM foods in particular. In short, the ethical concerns and challenges raised earlier on in this article have not been sufficiently dealt with within the legal framework, and therefore remain outstanding and legitimate.

\section{Conclusion}

There is no doubt that biotechnology and related technologies hold enormous potential in the fields of pharmaceuticals, medical care, agriculture and other areas. This in turn has unprecedented potential impact on human health and the natural environment. It is also not in doubt that GM technology promises novel responses to the perennial problem of food deficit, particularly in the third world. This notwithstanding, there are also legitimate concerns of possible risks associated with GM foods that may exceed those posed by conventionally produced foods.

This article has argued that like all other technological innovations, biotechnology is a human striving which cannot be stopped, but rather ought to be encouraged. It however raises fundamental ethical questions, challenges and even dilemmas that must be candidly confronted. It is only through such engagement that we can deploy such technological advancements to the service of the greater anthropogenic, biocentric and ecocentric good. 


\section{References}

Adenle, Ademola. 2011. "Response to Issues on Agriculture in Africa: Are Transgenic Crops Safe?" BMC Research Notes, Vol.4, p.388.

Barret, K. and G. Flora. 2000. "Genetic Engineering and the Precautionary Principle: Information for Extension". The Science and Environmental Health Network (SEHN) and The Institute for Agriculture and Trade (IATP). http//www.npsas.org/GEPraucationary.html

Batalion, N. 2000. 50 Harmful Effects of Genetically modified foods: Americans for safe food. New York: Oneonta.

Boss, Judith. 1999. Analyzing Moral Issues. Mountain View: Mayfield Publishing Company.

FAO. 2001. Genetically Modified Organisms, Consumers, Food Safety and the Environment. FAO Ethics Series 2. Rome: FAO.

Goklany, M.I. 2000. Applying the Precautionary Principle to Genetically Modified Crops. St. Louis: Centre for the Study of American Business.

Hilhorst, Medard. 1994. "The Ethical Assessment of New Technologies: Some Methodological Considerations". Wim Zweers and Jan Boersema eds. Ecology, Technology and Culture: Essays in Environmental Philosophy. Cambridge: The White Horse Press.

Juma, C. and J.Mugabe. Eds. 1994. Public Policy and New Generic Technologies: The Case of Biotechnology in Sub-Saharan Africa. Nairobi: Sida.

Kameri-Mbote, P. 2002. The Development of Biosafety Regulation in Africa in the Context of the Cartagena Protocol: Legal and Administrative Issues. Cowley Road: Blackwell Publishers Ltd.

--. 2004. "Towards a Liability and Redress System under the Cartagena Protocol on Biodiversity: A Review of the Kenya National Legal System". ACODE Policy Research Series No.8. ACODE, Kampala.

Kant, Emmanuel. 1952. Fundamentals of Metaphysics of Morals. Chicago: Encyclopedia Britannica Inc.

Kilbourne, E.M., R.M. Philen, M.L. Kamb and H. Falk. 1996. "Tryptophan Produced by Showa Denko and Epidemic Eosinophilia-Myalgia Syndrome". Journal of Rheumatology, Supplement 46, pp.81-91.

Kyalo, W. 2008. 'Stakeholders' Participation in Biotechnology Policy Formulation and their Perceptions towards Genetically Modified Foods in Nairobi Province, Kenya”. MPH Thesis, Kenyatta University.

Lappe, M. and B. Bailey. 1998. Against the Grain: Biotechnology and the Corporate Takeover of Your Food. N.P.: Common Courage Press.

McFague, Sallie. 1993. The Body of God: An Ecological Theology. Minneapolis: Fortress Press.

Newell, Peter and Dominic Glover. 2003. "Business and Biotechnology: Regulations and the Politics of Influence". IDS Working Paper 192. Institute of Development Studies (IDS), Brington.

Persley, G.J. 2003. New Genetics, Food and Agriculture: Scientific Discoveries Societal Dilemmas. Glasgow: The Doyle Foundation. 
Wrigley, A. 2007. "Proxy Consent: A Moral Authority Misconceived". Journal of Medical Ethics, Vol.33, pp.527-531.

SCBD. 1995. The Second United Nations Conference on Biodiversity 1995. Montreal: SCBD.

--. 2000. Cartagena Protocol on Biosafety to the Convention on Biological Diversity: Texts and Annexes. Montreal: SCBD.

Shannon, Thomas. Ed. 1993. Bioethics: Basic Writings on the Key Ethical Questions that Surround the Major, Modern Biological Possibilities and Problems. Mahwah, NJ: Paulist Press.

Tramper, Johannes and Young Zhu. 2011. Modern Biotechnology: Panacea or new Pandora's Box? Wageningen: Wageningen Academic Publishers.

WCED. 1987. Our Common Future: Report of the World Commission on Environment. New York: Oxford University Press.

WHO. 2005. Modern Food Biotechnology, Human Health and Development: Evidence-Based Study. Geneva: WHO. 